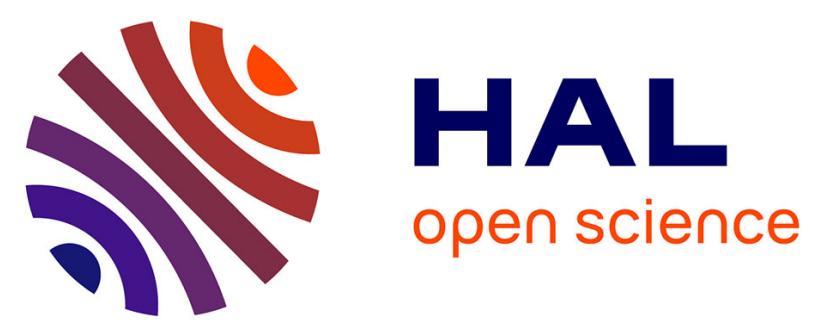

\title{
Stochastic models in floral biology and its application to the study of oilseed rape (Brassica napus L.) fertility
}

Wang Xiujuan, Amélie Mathieu, Paul-Henry Cournède, Jean-Michel Allirand, Alexandra Jullien, Philippe de Reffye, Bao Gui Zhang

\section{- To cite this version:}

Wang Xiujuan, Amélie Mathieu, Paul-Henry Cournède, Jean-Michel Allirand, Alexandra Jullien, et al.. Stochastic models in floral biology and its application to the study of oilseed rape (Brassica napus L.) fertility. Third International Symposium on Plant Growth Modeling, Simulation, Visualization and Applications (PMA09), Nov 2009, Beijing, China. inria-00529375

\section{HAL Id: inria-00529375 \\ https://hal.inria.fr/inria-00529375}

Submitted on 25 Oct 2010

HAL is a multi-disciplinary open access archive for the deposit and dissemination of scientific research documents, whether they are published or not. The documents may come from teaching and research institutions in France or abroad, or from public or private research centers.
L'archive ouverte pluridisciplinaire HAL, est destinée au dépôt et à la diffusion de documents scientifiques de niveau recherche, publiés ou non, émanant des établissements d'enseignement et de recherche français ou étrangers, des laboratoires publics ou privés. 


\title{
Stochastic models in floral biology and its application to the study of oilseed rape (Brassica napus L.) fertility
}

\author{
Xiujuan Wang ${ }^{* \ddagger}$, Amélie Mathieu ${ }^{\dagger}$, Paul-Henry Cournède ${ }^{\ddagger}$, \\ Jean-Michel Allirand ${ }^{\S}$, Alexandra Jullien ${ }^{\dagger}$, Philippe de Reffye ${ }^{\Uparrow}$ and Bao Gui Zhang* \\ * China Agricultural University, Key Laboratory of Plant-Soil Interactions, \\ College of Resources and Environment, 100193 Beijing - CHINA \\ ${ }^{\dagger}$ AgroParisTech, UMR EGC, INA-AgroParisTech, 78850 Thiverval-Grignon - FRANCE \\ ${ }^{\ddagger}$ Ecole Centrale de Paris, Laboratory MAS, 92290 Chatenay-Malabry - FRANCE \\ §INRA, UMR EGC, INA-AgroParisTech, 78850 Thiverval-Grignon - FRANCE \\ ${ }^{\top}$ CIRAD, AMAP and INRIA, DigiPlante, 34398 Montpelier - FRANCE \\ *Email: zhangbg@cau.edu.cn
}

\begin{abstract}
The number of seeds per pod is an important determinant of yield. New clues of yield and seed quality improvement can be provided by studying the relation between the developmental patterns of floral organs and seed production. In this article, a probabilistic model of plant inflorescence fertility is presented. From a biological point of view, seed development can be viewed as the combination of several physiological processes that can be modeled with stochastic laws. Experiments were made on oilseed rape in Grignon (France) in 2008 to calibrate the model. A Generalized Least Square method was implemented to estimate the model parameters. The variations of parameters were analyzed according to the position of flowers. Furthermore, we discussed the causes that lead to the variation of seed production within the inflorescence and related them to our model. The model reproduces well the distribution of the number of ovules per flower as well as the number of final seeds per pod. We deduced a law to describe the distribution of pollen grains on the stigma that is quite difficult to be observed experimentally. This model is the first step towards a dynamic model taking into account the complexity of the oilseed rape architecture, which is aimed to quantify the influence of pollination or trophic competition on seed production.
\end{abstract}

\section{Introduction}

In most flowering plants, only a minority of the flowers and ovules that are initiated form fruits and seeds [1], [2]. In those plants whose flowers are grouped into inflorescences, the size and number of reproductive structures show marked variations among flowers within the inflorescence. Numerous studies have investigated the relationships between reproductive effort and spatial position (proximal or distal), and time of opening (early or late) within the inflorescence [1], [3], [4]. During inflorescence development, the probability of fruit set and number of seeds per flower are often lower for distal/late-opening flowers than that for proximal/early-opening flowers [5]. Abortion of flowers and fruits occurs at various stages of development, and even in mature fruits [6]. Moreover, a fruit with too few seeds may abort [7], [8]. Various non-exclusive factors have been put forward to explain low fruit set in plant species, such as resource competition [1], [4], [6], non-uniform pollination [9], [10] and architectural effects [3], [11], [12].

To assess the divers factors controlling the seed production, the following four processes should be taken into consideration: the conditions of pollination, the number of ovules per ovary and its variability, the proportion of viable ovules and the relationship between the probability of pod abortion and the number of seeds per pod. All these are random processes that vary with season and genotype. Several models were performed to analyze the pollination and fertilization of flowers. De Reffye [7] observed the distribution of pollen grains on cacao trees and built a model of productivity to be combined with the experimental data. With a mathematical analysis of the data, it was shown that Pareto law was the most appropriate to simulate the distributions of number of pollen grains and Binomial distribution to compute the probability of an ovule developing into a seed for the cacao tree. Meanwhile, the relationship between the number of seeds per pod and the probability of fruit set could be computed with sigmoid function. Falque [13] studied the influences of the fertilization and the pollination on the plant productivity and modelled the relationship between pollination intensity and seed number per pod. Pollination and fruit growth in kiwifruit orchards were simulated by Lescourret [14]. The stochastic model 
calculates the amount of pollen grains deposited on pistillate flowers with Poisson law and the number of fertile ovules with Binomial distribution.

Based on the models presented above, we proposed a stochastic model of flower fertility and applied it to the study of oilseed rape fertility. Nowadays, the importance of oilseed rape production is growing and it has brought up research issues on seed yield and its quality improvement that have a great impact on oil, bio-fuel and lubricant production. Seed quality and quantity are strongly influenced by pollination, developmental patterns of floral organs and seed production [15]. The pollination is achieved with the assistance of various pollen vectors [16]. When oilseed rape comes into flower, the pollen is spread over large distances by insects, particularly the honey bees. Besides insects, wind plays an important role in the dispersal of oilseed rape pollen. Downey [17] found a high level of self-pollination in oilseed rape, because it was self-fertile and did not necessarily require cross-pollination to produce pods. However, several researchers [18], [19] indicated that the presence of bee hives significantly increased yields and quality in oilseed rape.

Regarding floral biology, oilseed rape is of great interest due to its sequence of flowering. Flowering lasts about one month inducing a big gap between the first emerged pods and the last ones. They are therefore subject to contrasting environmental conditions. The model we present here is only the first step towards a model integrating this temporal scale. Eventually we aim at estimating the impacts of time and space on seed yield and quality.

We first presented the stochastic model of the distribution of the number of seeds per pod by considering the processes of flower fertility, which include ovule distribution, pollen distribution, seed viability and pod abortion. After a statistical analysis of the data, we estimated the parameters by calibrating the model on experimental data. Furthermore, to study the effects of spatial position and opening time of flowers within the inflorescence, we analyzed the numbers of ovules and seeds per pod according to the position of flowers on the terminal raceme.

\section{Materials and Methods}

\subsection{Description of the model}

The different processes constituting flower fertility of oilseed rape are schematically represented in Fig. 1. The association of ovule and pollen is likely to create a seed but in some conditions there may be an abortion of the seed due to a fertility problem [6]. Therefore, reproductive success depends on the following parameters or processes:

(1) The number of ovules in the ovary;

(2) The number of pollen grains landing on the stigmas;

(3) The viability of seeds: not all the fertilized ovules can develop into mature seeds;

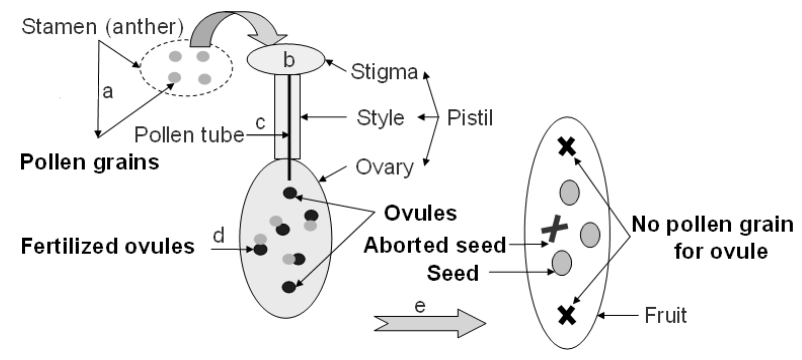

Figure 1. Schematic presentation of the events of seed development. Seed production involves several processes and floral components: pollen production by the anther, deposition of pollen grains (a) on the stigma (b), pollen germination and growth of the pollen tube (c), fertilization (d) and development of embryo and seed (e).

(4) The abortion of pods: pods with too few seeds may fall down.

These processes are modelled with probability laws. Firstly, the number of ovules in the ovary is supposed to be a random variable $Y$. Generally speaking, the normal distribution can be used to describe any variable that tends to cluster around the mean. It is a continuous probability distribution, here we have a discrete variable, thus we choose to describe the distribution of the number of ovules as a binomial law that has been proved to be appropriate with parameters $N$ and $b$, where $N$ is the maximum number of ovules and $b$ is the viable probability of an ovule. The probability that an ovary contains $y$ viable ovules is given by the following relationship:

$$
P(Y=y)=C_{N}^{y} b^{y}(1-b)^{N-y}
$$

Secondly, the number of pollen grains that arrive into a flower is described by the random variable $X$. Oilseed rape combines self- and cross- fertilization. Depending on variety and weather, oilseed rape is partially allogamous, exhibiting about 30\% outcrossing [20]. Outcrossing is mediated by both wind and insects and depends on the distance to the pollen source, wind direction and size of the field. Several probability laws (e.g. Pareto law, negative binomial law and lognormal law) have been compared and we choose here to present the lognormal law that best fits the data to compute the number of pollen grains. The lognormal distribution is defined by the probability density:

$$
f(x)=\frac{e^{-\frac{(\ln (x)-m)^{2}}{2 s^{2}}}}{x s \sqrt{2 \pi}}
$$

where $m, s$ are the parameters of the distribution. It is a continuous probability distribution function, whose discrete form is used in our model. According to the continuity cor- 
rection [21], we discretize it with the following relationship:

$$
P(X=x)=f(x+0.5)-f(x-0.5)
$$

$Z$ denotes the number of fertilized ovules. An assumption is made that for the fertilization of each ovule, one pollen grain is necessary and sufficient. Hence $Z=\min (X, Y)$ and the probability to get $y$ fertilized ovules is:

$$
\begin{aligned}
P(Z=y) & =P(X=y) P(Y>y) \\
& +\quad P(Y=y) P(X \geq y)
\end{aligned}
$$

Then, the fertilized ovules may develop into mature seeds with probability $p$ because of seed viability. If $S$ is the number of seeds, the probability to get $i$ seeds is:

$$
\begin{aligned}
P(S= & i)=\sum_{y=0}^{N} C_{y}^{i} p^{i}(1-p)^{y-i} P(Y=y) P(X \geq y) \\
& +\sum_{y=0}^{N} \sum_{k=i}^{y-1} C_{k}^{i} p^{i}(1-p)^{k-i} P(X=k) P(Y=y)
\end{aligned}
$$

The demonstration of equation 5 is given in appendix A. Lastly, if a pod contains too few seeds, then it may abort (and fall down). In a study of the frequency distribution of seed number in pods of Leucaena leucocephala (Lam), Ganeshaiah et al. [8] found that the formation of pods was related to the number of seeds in it. We compute the abortion probability of pods with a function $F$ that depends on the number of seeds per pod: a pod with a small number of seeds has a higher probability to abort. $B$ is the random variable of the final number of seeds per pod. The probability to get $i$ seeds per pod at this final stage is given by the following equation:

$$
P(B=i)=P(S=i) F(i)
$$

For the function $F$, we choose a beta law with parameters $\alpha, \beta$. This type of function is commonly used in biological models because of its flexibility, see [22] for an example. We recall that $N$ denotes the maximum number of ovules.

$$
\begin{gathered}
F(i)=\sum_{j=1}^{i} \frac{g(j)}{\sum_{l=1}^{N} g(l)} \\
g(j)=(j-0.5)^{\alpha-1}(N-j+0.5)^{\beta-1}
\end{gathered}
$$

By combining these laws, we can compute the final number of seeds per pod. The model has been developed in Scilab (INRIA-ENPC).

\subsection{Design of the experiment}

2.2.1. Plant and location. Oilseed rape (Brassica napus L.) is a bright yellow flowering member of the family Brassicaceae (mustard or cabbage family), which possesses a Brassica-typical crucifer cross-form petal arrangement, alternating with four sepals. The inflorescence is racemose, with indeterminate flowering beginning at the lowest bud on the main raceme and continuing upward during the following days. The flowers have one pair of lateral stamens with short filaments and four median stamens with longer filaments.

Oilseed rape (cultivar 'Mendel') was grown in Grignon (Yvelines, France, $48.9^{\circ} \mathrm{N}, 1.9^{\circ} \mathrm{E}$ ) at the National Institute for Agricultural Research (INRA) in $2007-2008$.

2.2.2. Experimental design. The flowering period of oilseed rape started in mid-April 2008 and lasted about one month. Measurements began in mid-May when all the flowers had developed into pods to make sure that we could analyze the final number of seeds in all the pods of the terminal raceme. To study the effects of position and opening time of flower on the amounts of ovules and seeds per pod on the main stem, 45 plants corresponding to 2050 pods, were sampled and all the pods on the main stem were measured from base to apex. Mature aborted seeds in each pod were counted and the positions of pods in each inflorescence were recorded. The number of ovules was the sum of mature and aborted seeds. At this stage, although the aborted seeds were visible in the pod, this measurement method might induce errors for small pods.

Analysis of variance (ANOVA) was applied to analyze the effects of flower position on the numbers of ovules and seeds and the effect of the number of ovules on that of seeds with the statistics software R.

\subsection{Parameter estimation}

The model parameters were estimated according to the experimental data. Table 1 summarizes the parameters of the model. Firstly, the parameters $N$ and $b$ were computed for the binomial distribution for the number of ovules. After that, the values of $N$ and $b$ were set to the estimated values and the parameters for the intensity of pollination, the viability of seeds and the abortion of pod were estimated simultaneously with the Generalized Least Square Method (GLSQR) [23].

Table 1. Model parameters

\begin{tabular}{lll}
\hline Processes & \multicolumn{1}{c}{ Distribution } & Parameters \\
\hline Ovules & Binomial distribution & $N, b$ \\
Pollen grains & Lognormal distribution & $m, s$ \\
Seed viability & Bernoulli process & $p$ \\
Pod abortion & Beta law & $\alpha, \beta$ \\
\hline
\end{tabular}




\section{Results}

\subsection{Numbers of ovules, seeds and aborted pods}

3.1.1. Numbers of ovules and seeds. Fig. 2 shows the average numbers of ovules and seeds with the standard deviation according to the rank. The average numbers of ovules and seeds per pod on the terminal raceme remains stable while that of seeds begins to decrease after the thirtieth rank.

ANOVA demonstrates that the flower position had no

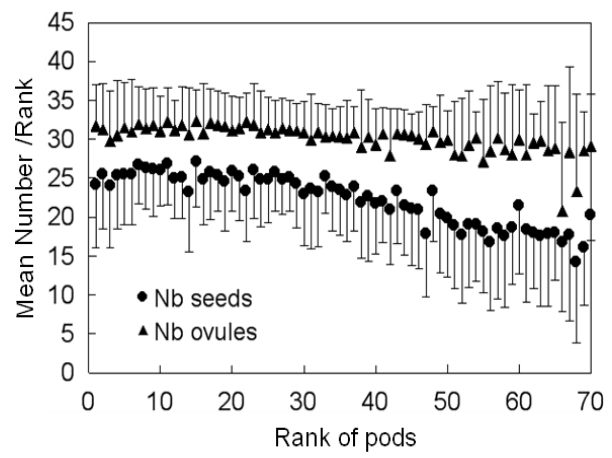

Figure 2. The average number of ovules and seeds per pod with standard deviation for each rank. Filled circles and triangles respectively represent the average numbers of ovules and seeds.

Table 2. Analysis of variance for the effects of the number of ovules and positions on the number of seeds per pod.

\begin{tabular}{llllll}
\hline & $D f$ & Sum Sq & Mean $S q$ & F value & $P(>F)$ \\
\hline Position & 69 & 8264 & 120 & 1.768 & $0.0002^{* * *}$ \\
Ovule & 21 & 1789 & 85 & 1.257 & 0.196 \\
Residuals & 752 & 50945 & 68 & & \\
\hline
\end{tabular}

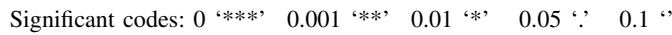

significant influence on the number of ovules per pod $(P>0.1)$, but it has great impact on the number of seeds per pod $(P<0.001)$. Besides, the number of ovules has no significant influence on that of seeds per pod $(P>0.1)$ (Table 2).

3.1.2. Number of aborted pods. The number of aborted pods on the terminal raceme remains stable until the fortieth rank. Upwards, it increases linearly with raceme rank (Fig. 3 ). It seems that the increase in the abortion of pods starts at the same time as the decrease in the number of seeds per pod. Therefore, we chose to restrict our data set for the following of the study and mainly the model calibration: we focused on the distribution of the seeds of pods with rank lower than forty.

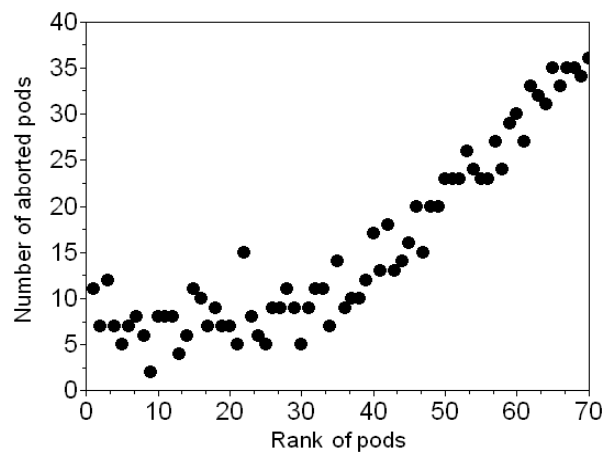

Figure 3. Number of aborted pods for each rank.

\subsection{Model calibration}

We estimated the parameters of the binomial distribution giving the number of ovules per flower according to the experimental data. As shown in Fig. 4, the distribution of ovules is well adjusted, the Pearson product-moment correlation coefficient between observed and computed number of ovules is $r=0.95$. The average number of ovules in a flower is 31.5 , with a standard deviation of 10.96 . It is a coefficient of variation of 0.34 , which corresponds to a fairly wide dispersion around the mean value. The variability of the number of ovules in a flower can be due to earlier abortion or the initial conditions at the flower appearance.

We set the parameters of ovule distribution to the values $N=54, b=0.59$, and fit the number of seeds per pod. Table 3 gives the values of parameters. Fig. 4 shows the

Table 3. Estimated parameters of the fertility model.

\begin{tabular}{ccclccccc}
\hline Process & \multicolumn{2}{c}{ Ovule number } & \multicolumn{2}{l}{ Pollen number } & \multicolumn{2}{c}{ Seed viability } & \multicolumn{2}{c}{ Pod abortion } \\
& $N$ & $b$ & $m$ & $s$ & $p$ & $\alpha$ & $\beta$ \\
\hline Values & 54 & 0.59 & 3.7 & 1.42 & 0.80 & 4.0 & 15.0 \\
\hline
\end{tabular}

distribution of the number of ovules and seeds. The Pearson product-moment correlation coefficient between observed and computed number of seeds is $r=0.975$. Fig. 4 shows the shift of distributions between ovules and seeds corresponding to the flower fertility. As described in section 2.1, mathematically the shift results from two factors: the viability of ovules and pollination. Firstly, the probability of a fertilized ovule developing into a seed is less than 1 . The curve of ovules is transformed into the curve of seeds. Secondly, we took the smaller value of ovules and pollen grains into account to compute the number of fertilized ovules. The shift of the curve of seed number distribution was due to the lack of pollen, especially the left side.

The number of aborted pods is not fitted by the model, but we had a very good match between the observed values and the computed ones (Fig. 4a). It means that our model can explain all the pod abortion, without introducing a specific law to take into account the trophic competition. 


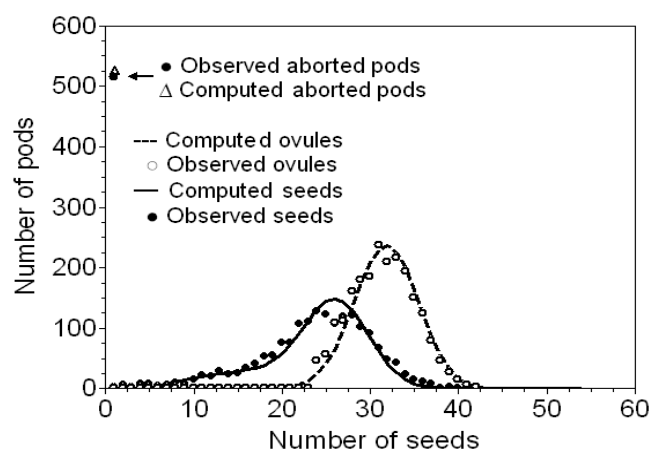

(a)

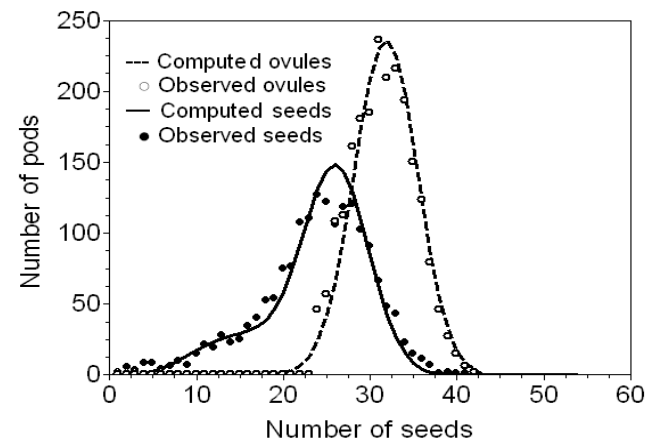

(b)

Figure 4. (a). Distributions of ovules and seeds with the data corresponding to pod abortion. (b). Distributions of ovules and seeds with data of aborted pods not included. Mean $=23.9, S T D=7.789$. Dashed line and open circles represent respectively the computed and observed ovules distributions; Solid line and filled circles represent respectively the computed and observed seed distributions.

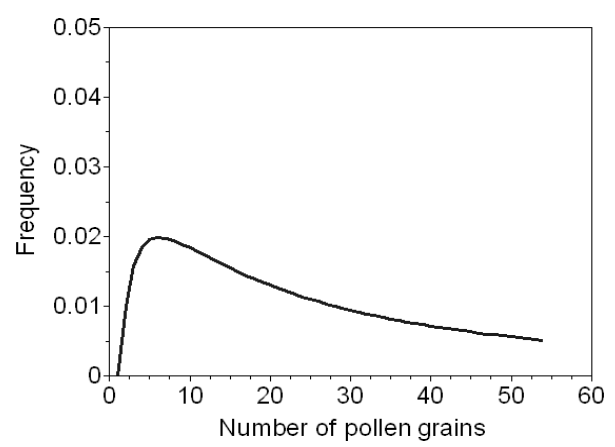

Figure 5. Simulated distribution of pollen grains.

We did not count the number of pollen grains because of the difficulty in measuring. Here we gave the theoretical probability of pollen grain that arrive into a flower, as shown in Fig.5.

\subsection{Variation of under-pollination index according to the pod rank on the terminal raceme}

Index of under-pollination is defined as the probability for a flower to receive less pollen grains than the number of ovules it contains (see appendix B). With the estimated parameters, we got a value of 0.44 for under-pollination, which is surprisingly quite high. We plan to pollinate plants by hand to compare natural and manual pollination.

The variation of under-pollination index in the model according to the pod rank is shown in Fig. 6.

The parameters of distribution for pollen grains $(m, s)$ are

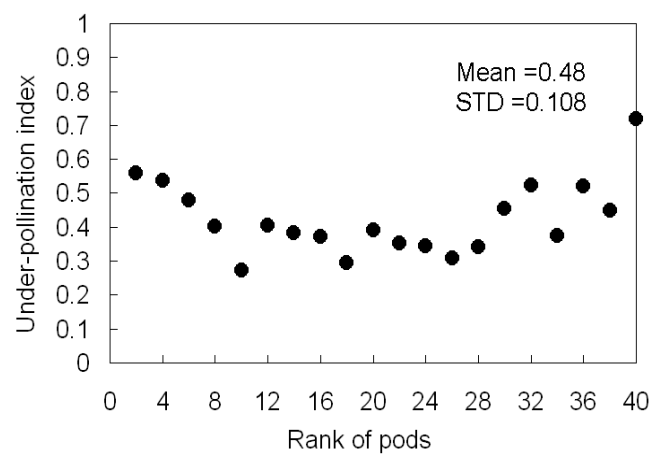

Figure 6. The variation of under-pollination index according to the pod rank.

estimated according to the pod rank. The under-pollination index is computed with the equation of appendix B. As shown in Fig. 6, it is a little bit large at the beginning, then relatively stable until rank thirtieth, but increases at the end of flowering period. From the result, it can be deduced that pollination is variable according to the rank $(S T D=0.108)$. To verify if the variation of the index is resulted from the sample size, a Monte Carlo simulation with the same conditions as the experiment has been done to reconstruct Fig. 6. The result indicates that the variability could be due to the climatic conditions but not to the sample size.

\section{Discussion}

A stochastic model of flower fertility of oilseed rape was proposed in this article. It computed the number of seeds per pod by combining several stochastic processes. The parameters were estimated from experimental data with a Generalized Least Square method and their variations according to the positions of the flowers on the terminal raceme were calculated. It allowed us to analyze the factors that lead to the abortion of pods and seeds.

The average number of ovules per pod remains stable while that of seeds decreases from the base to the top of the stem. Flowers from the apical region contain fewer 
seeds than the flowers from the basal region. This result is consistent with our hypothesis that time has an influence on seed production, as the lowest flowers appear earlier the highest ones. The maturity and/or the receptivity of the ovules at time of flower opening may be important for determining ovule fertility, and therefore, seed set ([24]). The conditions experienced by the flower buds when the ovules were fertilized at flower opening are of crucial importance to determine seed number per pod [25].

Pod abortion remains stable until fortieth rank and increased afterwards. The phenomenon is consistent with the study of [26], in which a few flowers fail to form pods at the beginning of flowering in the middle of April, but the ratio of pod to opened flower soon reaches and remains at 1:1 until early May and decrease progressively to less than 0.3:1 at the end of flowering. The results suggest that the greater rate of abortions for pods and seeds in late-formed flowers are not the result of a small number of ovules per pod.

Moreover, the shift of distribution between ovules and seeds (Fig. 4) might be resulted from either by insufficient pollination or smaller viability of ovule.

Accordingly, reproductive failure may be caused by nonuniform pollination, reduction of ovule fertility in the most distal location, depletion of resource (assimilate) by early developed seeds, or architectural effects.

Ovule fertility. Ovule fertility is described as the percentage of ovules with complete embryo sacs at flower opening [25]. Generally speaking, thirty percent of the ovules are sterile due to the absence of an embryo sac [25]. Within the terminal raceme, decreased ovule fertility due to the sterility of ovules is one of the causes for the lower number of seeds per pod in the apical region compared to the basal region. If the proportion of ovules with embryo sac decreases according to the rank, pollination will be incomplete even if the amount of pollen grains is large, because not all the ovules of a pod will be fertilized. Thus, ovule fertility is responsible for the lower number of seeds of late flowers.

Non-uniform pollination. For a successful fertilization of all the ovules in a pod, several factors are essential. Firstly, sufficient amounts of pollen are needed (equal or superior to the ovule number) to be deposited on the stigma; secondly, the pollen grains have to germinate and a pollen tube to grow out (Fig. 1). Thus the failure of seed production may be caused by either reduced pollen production or poor pollen quality [9]. The decrease in pollen production can be the consequence of decreasing number of flowers or/and inefficient pollinators. Indeed, most flowers develop into pods at the end of the flowering period and the terminal raceme gradually stops growing, which lead to a lower number of flowers in the field, and hence a reduced amount of pollen grains for late flowers. Moreover, dispersal of pollen depends on the insects, and a lower number of flowers thus attract fewer insects. Furthermore, the quantity of pollen in the air is influenced strongly by weather conditions, such as wind, temperature and precipitation [10]. In our model, the index of under-pollination varies according to the flower location which could be the effect of lack of pollen.

Resource competition vs. architectural effects. Another possible cause of abortion of late flowers is the depletion of resources by early developed pods within the inflorescence. As speculated by the resource competition hypothesis [1], [4], [6], there is competition among the ovaries of an inflorescence for a limited amount of resources. Flowers located near the base of the inflorescence open and get pollinated first, thus, their fruits would have more chances to survive and acquire more available resources to sustain their growth. Furthermore, the organs (leaves and pods) loss progressively their photosynthetic capacity, there is thus insufficient assimilate to fill the pods at the end. Mutual shade and utilization of assimilates by large pods containing rapidly growing seeds could also be the causes for decreasing resources. In the study of Medrano et al. [3] in Pancratium maritimum, removal of flowers from inflorescences improved the fruit and seed set of the remaining flowers by comparison with flowers in the same position on control inflorescence. This suggested that the flowers in an inflorescence compete for resources. However, the removal of early flowers does not significantly increase the fruit set of late flowers, which could be attributable to architectural effect [3], [11]. The ability of reproduction for flowers locating at different positions (main stem vs. ramifications or proximal vs. distal) may be different. Architectural effects could result from the lower maximum fruit set of main stem than that of ramifications or of late-opening flowers than that of early-opening ones. Therefore, more detailed experiments need to be done for analyzing its effect for oilseed rape.

The characteristics of ovule number, seed number and pod abortion are points to understand the fertility of oilseed rape, we intend to integrate the spatial (position on the main stem and ramifications) and temporal scales in the model. As a consequence, experiments are currently conducted to parameterize this more complex model. Experiments will be designed in terms of the causes mentioned above, and are foreseen to get a better understanding of the effects of time and position in the plant on seed production. These experimental data will be integrated into the dynamic model.

\section{Acknowledgements}

The authors would like to thank the people from INRAEGC involved for their kind assistance on experiments. This study was supported by Chinese Ministry of Science 
and Technology in the project of National High Technology of Research and Development of China (grant No $2006 A A 10 A 303-1$ ), and was partly supported by China Scholarship Council (CSC), which provides the PhD scholarship of Xiujuan Wang.

\section{Appendix A. Formula for computing the probability of seed number}

$X, Y$ and $Z$, respectively, denote the numbers of pollen grains, ovules and fertilized ovules. We assume in the model that $Z=\min (X, Y)$. Hence, we recall the equation [4]:

$$
P(Z=k)=P(X=k) P(Y>k)+P(Y=k) P(X \geq k)
$$

We use the theory of total probability to write the probability to get $k$ fertilized ovules:

$$
\begin{gathered}
P(Z=k)=\sum_{y=0}^{N} P(Z=k / Y=y) P(Y=y) \\
P(Z=k)=\sum_{y=0}^{N} P(\min (X, Y)=k \mid Y=y) P(Y=y) \\
P(\min (X, Y)=k / Y=y)= \begin{cases}0 & k>y \\
P(X=k) & k<y \\
P(X \geq k) & k=y\end{cases}
\end{gathered}
$$

Hence we have:

$$
P(Z=k)=P(Y=k) P(X \geq k)+\sum_{y=k+1}^{N} P(X=k) P(Y=y)
$$

Lastlty, we assume that the number $S$ of fertile ovules depends on $Z$ with a Bernoulli process of parameter $p$, which means that:

$$
P(S=i / Z=k)=C_{k}^{i} p^{i}(1-p)^{k-i}
$$

Likewise, we use the theory of total probability to compute the law of the random variable $S$ :

$$
\begin{aligned}
P(S=i) \quad & =\sum_{k=i}^{N} P(S=i / Z=k) P(Z=k) \\
& =\sum_{k=i}^{N} C_{k}^{i} p^{i}(1-p)^{k-i} P(Z=k) \\
& =\sum_{k=i}^{N} C_{k}^{i} p^{i}(1-p)^{k-i} P(Y=k) P(X \geq k) \\
& +\sum_{k=i}^{N} C_{k}^{i} p^{i}(1-p)^{k-i} \sum_{y=k+1}^{N} P(X=k) P(Y=y) \\
& =\sum_{y=0}^{N} C_{y}^{i} p^{i}(1-p)^{y-i} P(Y=y) P(X \geq y) \\
& +\sum_{y=0}^{N} \sum_{k=i}^{y-1} C_{k}^{i} p^{i}(1-p)^{k-i} P(X=k) P(Y=y)
\end{aligned}
$$

\section{Appendix B. Index of under-pollination}

We define the index of under pollination as the probability for a flower to get less pollen grains than that of ovules: $P(X<Y) . X$ and $Y$ respectively denote the number of pollen grains and ovules per flower. We can determine the index of under-pollination:

$$
\begin{aligned}
P(X<Y) & =\sum_{y=0}^{N} P(X<Y=y) P(Y=y) \\
& =\sum_{y=0}^{N} \sum_{x=0}^{y} P(X=x) P(Y=y) \\
& =\sum_{y=0}^{N} \sum_{x=0}^{y} P(X=x) C_{N}^{y} b^{y}(1-b)^{N-y}
\end{aligned}
$$

\section{References}

[1] T. Lee, "Patterns of fruit and seed production." in Plant Reproductive Ecology: Patterns and Strategies, J.Lovett Doust and L. Lovett Doust [eds.] ed. Oxford University Press, New York, NY, USA, 1988, pp. 179-202.

[2] A. Mathieu, B. Zhang, E. Heuvelink, S. Liu, P. Cournède, and P. de Reffye, "Calibration of fruit cyclic patterns in cucumber plants as a function of source-sink ratio with the greenlab model," in FSPM07, Napier, New Zealand, J. H. Przemyslaw Prusinkiewicz and B. Lane, Eds., November 2007.

[3] M. Medrano, P. Guitián, and J. Guitián, "Patterns of fruit and seed set within inflorescences of Pancratium maritimum (Amaryllidaceae): Nonuniform pollination, resource limitation, or architectural effects?" American Journal of Botany, vol. 87(4), pp. 493-501, 2000.

[4] A. Stephenson, "Fruit set, herivory, fruit reduction and fruiting strategy of Catalpa speciosa (Bignoniaceae)," Ecology, vol. 61, pp. 57-64, 1980.

[5] J. Guitián and L. Navarro, "Allocation of reproductive resources within infllorescences of Petrocoptis grandiflora (Caryophyllaceae)," Canadian Journal of Botany, vol. 74, pp. 1482-1486, 1996.

[6] H. Arathi, R. Ganeshaiah, U. Shaanker, and S. Hegde, "Seed abortion in Pongamia pinnata (Fabaceae)," American Journal of Botany, vol. 86(5), pp. 659-662, 1999.

[7] P. de Reffye, J. Parvais, G. Mossu, and P. Lucas, "Influence des aléas de la pollinisation sur les rendements du cacaoyer modèle mathématique et simulation," Café Cacao Thé, vol. 22(4), pp. 251-274, 1978.

[8] K. Ganeshaiah, R. Shaanker, and G. Shivashankar, "Stigmatic inhibition of pollen grain germination-its implication for frequency distribution of seed number in pods of Leucaena leucocephala (Lam) de Wit," Oecologia, vol. 70, pp. 568$572,1986$. 
[9] R. Berjano, C. de Vega, M. Arista, P. Ortiz, and S. Talavera, "A multi-year study of factors affecting fruit production in Aristolochia paucinervis (Aristolochiaceae)," American Journal of Botany, vol. 93(4), pp. 599-606, 2006.

[10] S. Gruber and W. Claupein, "Fecundity of volunteer oilseed rape and estimation of potential gene dispersal by a practicerelated model," Agriculture, Ecosystems and Environment, vol. 119, pp. 401-408, 2007.

[11] P. Diggle, "Architectural effects and the interpretation of patterns of fruit and seed development," Annual Review of Ecology and Systematics, vol. 26, pp. 531-532, 1995.

[12] E. Vallius, "Position-dependent reproductive success of flowers in Dactylorhiza maculata (Orchidaceae)," Functional Ecology, vol. 14, pp. 573-579, 2000.

[13] M. Falque, A. Vincent, B. Baissiere, and A. Eskes, "Effect of pollination intensity on fruit and seed set in cacao (Theobroma cacao L.)," Sex Plant Reprod, vol. 8, pp. 354-360, 1995.

[14] F. Lescourret, R. Habib, M. Génard, D. Agostini, and J. Chadoeuf, "Pollination and fruit growth models for studying the management for kiwifruit orchards. I. Models description," Agricultural Systems, vol. 56, pp. 67-89, 1998.

[15] S. Teixeira, R. Pereira, and N. Ranga, "Components of fecundity and abortion in a tropical tree, Dahlstedtia pentaphylla (Leguminosae)," Brazilian Archives of Biology and Technology, vol. 49, pp. 905-913, Nov 2006.

[16] R. Sabbahi, D. de Oliveira, and J. Marceau, "Influence of honey bee (hymenoptera: Apidae) density on the production of canola (Crucifera: Brassicacae)," Journal of Economic Entomology, vol. 98(2), pp. 367-372, 2005.

[17] R. Downey, "Effect of bees on seed yields of arlo rapeseed," Forage Notes, vol. 10, p. 1, 1964.

[18] J. Free and P. Nuttal, "The pollination of oilseed rape (Brassica napus) and the behaviour of bees on the crop," Journal of Agricultural Sciences, vol. 71, pp. 91-94, 1968.

[19] I. Williams, "The pollination of swede rape (Brassica napus 1.)," Bee World, vol. 66, pp. 16-22, 1985.

[20] H. Becker, C. Damgaard, and B. Karlsson, "Environmental variation for outcrossing rate in rapeseed (Brassica napus)." Theorectical and Applied Genetics, vol. 84, pp. 303-306, 1992.

[21] de Joseph L. F., A. L. Bruce, and C. Myunghee, Statistical methods for rates and proportions. Columbia University, 2003.

[22] Y. Yin, J. Goudriaan, E. Lantinga, J. Vos, and H. Spiertz, "A flexible sigmoid function of determinate growth," Annals of Botany, vol. 91, pp. 361-371, 2003.

[23] Z. Zhan, P. de Reffye, F. Houllier, and B. Hu, "Fitting a structural-functional model with plant architectural data," in Hu B.G., Jaeger M., eds. Proceeding of Plant Growth Modeling and Applications (PMA'03). Beijing, China. Tsinghua University Press/Springer-Verlag, 2003, pp. 236-249.
[24] S. Ancha, "Analysis of factors influencing pod and seed development in oilseed rape (Brassica napus L.)," PhD thesis, 1988.

[25] C. Bouttier and D. Morgan, "Ovule development and determination of seed number per pod in oilseed rape (Brassica napus L.)," Journal of Experimental Botany, vol. 43, pp. 709714, May 1992.

[26] E. Lefol, V. Danielou, and H. Darmency, "Predicting hybridization between transgenic oilseed rape and wild mustard," Field Crops Research, vol. 45, pp. 153-161, 1996. 